\title{
BMJ Open Preoperative iron treatment in anaemic patients undergoing elective total hip or knee arthroplasty: a systematic review and meta-analysis
}

\author{
Ashley B Scrimshire (D) , ${ }^{1,2}$ Alison Booth (D) , ${ }^{1}$ Caroline Fairhurst, ${ }^{1}$ Alwyn Kotze ${ }^{3}$ \\ Mike Reed, ${ }^{2}$ Catriona McDaid (i) ${ }^{1}$
}

To cite: Scrimshire $A B$, Booth $A$, Fairhurst $\mathrm{C}$, et al. Preoperative iron treatment in anaemic patients undergoing elective total hip or knee arthroplasty: a systematic review and meta-analysis. BMJ Open 2020;10:e036592. doi:10.1136/ bmjopen-2019-036592

- Additional material is published online only. To view please visit the journal online (http://dx.doi.org/10.1136/ bmjopen-2019-036592).

Received 05 January 2020 Revised 03 September 2020 Accepted 08 September 2020

Check for updates

(c) Author(s) (or their employer(s)) 2020. Re-use permitted under CC BY-NC. No commercial re-use. See rights and permissions. Published by BMJ.

${ }^{1}$ Department of Health Sciences, University of York, York, UK ${ }^{2}$ Northumbria Healthcare NHS Foundation Trust, Ashington, UK ${ }^{3}$ Leeds Teaching Hospitals, Leeds, UK

Correspondence to Ashley B Scrimshire; Ashley.Scrimshire@nhs.net

\section{ABSTRACT}

Objectives Preoperative anaemia is associated with increased risks of postoperative complications, blood transfusion and mortality. This meta-analysis aims to review the best available evidence on the clinical effectiveness of preoperative iron in anaemic patients undergoing elective total hip (THR) or total knee replacement (TKR).

Design Electronic databases and handsearching were used to identify randomised and non-randomised studies of interventions (NRSI) reporting perioperative blood transfusion rates for anaemic participants receiving iron before elective THR or TKR. Searches of CENTRAL, MEDLINE, Embase, PubMed and other databases were conducted on 17 April 2019 and updated on 15 July 2020. Two investigators independently reviewed studies for eligibility and evaluated risk of bias using the Cochrane risk of bias tool for randomised controlled trials (RCTs) and a modified Newcastle-Ottawa scale for NRSIs. Data extraction was performed by $A B S$ and checked by $A B$. Meta-analysis used the Mantel-Haenszel method and random-effects models.

Results 807 records were identified: 12 studies met the inclusion criteria, of which 10 were eligible for metaanalyses (one RCT and nine NRSIs). Five of the NRSIs were of high-quality while there were some concerns of bias in the RCT. Meta-analysis of 10 studies $(n=2178$ participants) showed a $39 \%$ reduction in risk of receiving a perioperative blood transfusion with iron compared with no iron (risk ratio $0.61,95 \% \mathrm{Cl} 0.50$ to $0.73, \mathrm{p}<0.001$, $\mathrm{I}^{2}=0 \%$ ). There was a significant reduction in the number of red blood cell units transfused with iron compared with no iron (mean difference -0.37 units, $95 \% \mathrm{Cl}-0.47$ to $\left.-0.27, p<0.001, I^{2}=40 \%\right)$; six studies $(n=1496)$. Length of stay was significantly reduced with iron, by an average of 2.08 days $\left(95 \% \mathrm{Cl}-2.64\right.$ to $\left.-1.51, \mathrm{p}<0.001, \mathrm{I}^{2}=40 \%\right)$; five studies $(\mathrm{n}=1140)$.

Conclusions Preoperative iron in anaemic, elective THR or TKR patients, significantly reduces the number of patients and number of units transfused and length of stay. However, high-quality, randomised trials are lacking.

PROSPERO registration number CRD42019129035.
Strengths and limitations of this study

- This review has a pragmatic approach to inclusion criteria and is focused on one particular type of elective surgery, which is considered as one of the most appropriate fields for preoperative anaemia optimisation.

- Comprehensive database and handsearching techniques have been employed to identify the best available evidence on this topic, and rigorous sensitivity analyses of results have been undertaken.

- The results of this review are limited by the quality of the included studies. A lack of well-conducted randomised controlled trials means insufficient evidence is available to reliably inform future clinical practice or guideline development.

- The quality of reporting in the included studies, particularly around the underlying cause of anaemia, other coexisting patient blood management strategies and patient adherence also limit the results of this review.

\section{INTRODUCTION}

Over 175000 primary, elective total hip (THR) or total knee replacements (TKR) were performed in the UK in 2018-2019. ${ }^{1}$ Up to one in three of those patients would be expected to have preoperative anaemia, the majority of which is caused by absolute or functional iron deficiency in this population. ${ }^{2-6}$ Preoperative anaemia is an independent risk factor for increased perioperative complications, mortality, allogenic red blood cell (RBC) transfusion and longer length of hospital stay $(\mathrm{LoS}){ }^{7}$ RBC transfusion itself is also independently associated with poorer postoperative outcomes and longer LoS. ${ }^{7}$ Elective orthopaedic surgery is described as one of the most appropriate fields for implementation of preoperative anaemia optimisation. ${ }^{8}$ Erythropoietin (EPO) is one option for optimising preoperative anaemia; however, there are concerns that routine use is not cost 
effective. ${ }^{9}{ }^{10}$ The National Institute for Health and Care Excellence in the UK and multiple international guidelines recommend iron treatment(s) be used to optimise anaemia caused by iron deficiency, in the preoperative period. ${ }^{10-13}$ However, a recent report from the Royal College of Anaesthetists found $70 \%$ of anaemic patients received no treatment for anaemia in the 3 months before surgery. ${ }^{14}$

There is mounting evidence that multimodal patient blood management (PBM) programmes can be effective at improving postoperative outcomes and reducing perioperative blood transfusions and costs. ${ }^{15} 16$ A PBM programme typically consists of three 'pillars'; (1) optimising red cell mass, (2) reducing blood loss and (3) harnessing and optimising physiological reserve of anaemia. ${ }^{17}$ While some elements of PBM have a strong evidence base in hip or knee replacement, such as the use of tranexamic acid (TXA) ${ }^{18}$ and reduced transfusion thresholds,$^{19}$ the evidence for preoperative anaemia optimisation with iron is less robust. ${ }^{13}$ This coupled with organisational barriers and misconceptions around treatment options may be contributing to poor uptake. ${ }^{20} 21$

The question addressed by this review is, does preoperative iron improve postoperative blood transfusion rates and outcomes, in patients with preoperative anaemia undergoing primary, elective THR or TKR? Although the majority of preoperative anaemia in this population is likely to be due to iron deficiency, iron alone will not address preoperative anaemia for all patients and guidelines recommend the underlying cause of anaemia should be ascertained before starting treatment. ${ }^{231013} \mathrm{In}$ recognition that iron will not be appropriate for all patients and in an attempt to make the results more generalisable, we included studies using another intervention to treat preoperative anaemia, such as EPO, for up to $20 \%$ of participants. This figure is based on a multicentre cohort study showing approximately $85 \%$ of preoperative anaemia in elective surgical patients is due to iron deficiency (functional or absolute) or low iron stores, and may respond to iron. ${ }^{2}$

\section{METHODS}

CENTRAL, MEDLINE, Embase, PubMed, ISI Web of Science, Transfusion Library, ClinicalTrials.gov, ICTRP, ISRCTN and ProQuest databases were searched using the search strategies in online supplemental appendix 1A. An example of search terms used include ("iron" OR "iron compounds" OR "ferrous compounds" OR "ferric compounds") AND ("anemia" OR "anemia, iron deficiency") AND ("preoperative period" OR "preoperative care" OR perioperative period" OR "preoperative care") AND ("orthopedics" OR "hip" OR "hip joint OR "hip prosthesis" OR "arthroplasty, replacement, hip" OR "knee" OR "knee joint" OR "knee prosthesis" OR "arthroplasty, replacement, knee"). Searches were performed on 17 April 2019 with no date or language restrictions applied and were updated on 15 July 2020.
The reference lists of the most recent clinical guidelines for preoperative anaemia from Europe, Australia and the USA, existing systematic reviews on a similar topic and expert opinion pieces were scanned for additional studies. Abstracts from relevant conferences from January 2009 to April 2019 were hand searched, and field experts and relevant pharmaceutical companies were contacted to obtain any unpublished trials. Where trial protocols were found by the searches we also searched for any results papers. Forward and backward reference searching of the included studies was performed. Search results were collated in Covidence systematic reviews software (Veritas Health Innovation, Melbourne, Australia).

This review includes randomised controlled trials (RCTs) and non-randomised studies of interventions (NRSI) with a control group that report perioperative blood transfusion rates for adult, anaemic participants who received iron treatment (enteral or parenteral) before undergoing elective THR or TKR. Anaemia is traditionally defined as haemoglobin $(\mathrm{Hb})$ values less than $130 \mathrm{~g} / \mathrm{L}$ for males and $120 \mathrm{~g} / \mathrm{L}$ for non-pregnant females. ${ }^{22}$ However, in recognition of views that a nongender based cut-off of $130 \mathrm{~g} / \mathrm{L}$ for males and females is more appropriate, ${ }^{12}$ we accepted any clear definition of anaemia by the study investigators. Eligible comparators were another form of iron treatment, placebo, no anaemia treatment or standard care.

The primary outcome was perioperative blood transfusion rate. Other outcomes of interest were quantity of blood transfused (units), change in $\mathrm{Hb}$ or ferritin concentration, morbidity including infection and other adverse events, mortality, LoS, critical care admission rate, readmission rate, compliance with iron and any validated quality of life (QoL) measure. Studies that include participants undergoing THR or TKR following trauma or where the intervention included autologous transfusion methods were excluded.

Following deduplication, two authors ( $\mathrm{ABS}$ and $\mathrm{AB}$ ) independently reviewed titles and abstracts to assess study eligibility against the predefined criteria. Full manuscripts of any potentially eligible records were obtained and screened using the same method. Multiple accounts of the same study were excluded. A record of excluded studies is provided in online supplemental appendix 1B.

One author (ABS) extracted data from each study using a prepiloted data extraction form. Data were checked by a second author $(\mathrm{AB})$. Disagreements on inclusion of studies and data extractions were discussed and a consensus reached. Where information was unclear, attempts were made to contact study authors for further details. Where available as a subgroup, only data for participants receiving iron were extracted.

The two reviewers (ABS and $\mathrm{AB}$ ) independently assessed the risk of bias and quality of studies using the Cochrane Risk of Bias (RoB2) tool for randomised studies and the Newcastle-Ottawa scale (NOS) for NRSIs. ${ }^{23} 24$ Again, disagreements were discussed, and a consensus reached. A modified version of the NOS, 
excluding fields of 'demonstration that outcome of interest was not present at start of study' and 'was follow-up long enough', was used as these were not applicable to this review. The maximum score using our modified NOS is 7 stars. To reduce variability in applying the NOS between authors, detailed criteria were developed specific to this review (see online supplemental appendix 1C).

Standard criteria for defining high-quality or lowquality studies using this modified NOS do not exist. For this review, studies scoring $\leq 4$ stars or at high risk of bias on RoB2 were defined as being of low quality. This is based on a previous review which used a similarly modified NOS. ${ }^{25}$

We planned to perform meta-analysis of postoperative outcomes and where sufficient data were available, subgroup analyses comparing types of iron, types of surgery and the use of concurrent treatments. However, sufficient data were only available to perform subgroup analysis for different types of iron. To control for the one study that used EPO in two participants, it was excluded as part of the sensitivity analyses. In addition, we undertook an exploratory analysis of correlation between preiron $\mathrm{Hb}$ and type of iron treatment on the change in $\mathrm{Hb}$ concentration following iron. We have also conducted sensitivity analyses to assess the robustness of our results.

Meta-analysis was undertaken using Review Manager V.5.3 (The Cochrane Collaboration, Oxford, UK). The Mantel-Haenszel method was employed using risk ratios (RR). A random-effects model was used due to expected methodological heterogeneity among studies in relation to iron drug, dose and timing, definitions of anaemia and transfusion thresholds. Mean differences (MD) were calculated where appropriate depending on homogeneity of units of reporting (ie, RBC units). The $\mathrm{I}^{2}$ statistic was used to assess heterogeneity. In keeping with previous Cochrane reviews, moderate and substantial heterogeneity were defined as an $\mathrm{I}^{2}$ of more than $50 \%$ or $85 \%$, respectively. ${ }^{19} 26$

Differences were seen in how studies reported data on the number of RBC units transfused. Some studies reported an average only for the subpopulation who received a transfusion and others an average for the entire cohort undergoing surgery. In studies reporting only for those who had a transfusion, it is known the rest of that cohort population, those not transfused, all received zero RBC units. In order to allow meaningful pooling of results, methods of combining means were used to convert these into averages for the entire cohort undergoing surgery (online supplemental appendix 1D).

This review includes studies with any clear definition of anaemia, this resulted in the inclusion of two studies in which participants have a presenting Hb level (130$140 \mathrm{~g} / \mathrm{L}$ ) that by traditional WHO definitions would be considered non-anaemic. ${ }^{27-30}$ It is also thought intravenous iron leads to a greater $\mathrm{Hb}$ increase than oral iron. ${ }^{30}$ Subgroup and meta-regression analyses were performed to investigate these associations further.
When pooling data on pre-iron and post-iron $\mathrm{Hb}$ concentrations, correlation is expected as these data are from the same participants. As such, a correlation coefficient (CC) is required to accurately calculate a $\mathrm{MD}$ and variance. As no published $\mathrm{CC}$ were identified, these were calculated for oral (0.56) and intravenous (0.70) iron from a local dataset, made available to reviewers. ${ }^{31}$ Comprehensive Meta-analysis (V.2, Biostat, USA) was used to calculate the MD, SD and SE for each study reporting pre-iron and post-iron $\mathrm{Hb}$ data and meta-regression was performed in Stata (V.15.1 StataCorp) using the 'metareg' command. ${ }^{32}$

In accordance with recommendations from the Cochrane Collaboration, as 10 studies were included in the meta-analysis of the primary outcome a funnel plot was generated and visually inspected to assess for publication bias. ${ }^{26}$ For all statistical tests a $\mathrm{p}<0.05$ was considered statistically significant. Sensitivity analysis of the pooled results was performed excluding studies where the underlying cause of anaemia was not specifically reported as being iron deficiency; low-quality studies; those with any imputed data; those using a concurrent anaemia treatment (ie, EPO); and those with an average presenting $\mathrm{Hb}$ $>130 \mathrm{~g} / \mathrm{L}$.

Where studies report outcomes separately for oral and IV iron, outcomes were analysed separately for the effects on $\mathrm{Hb}$ concentration, but the oral and intravenous groups data were combined for inclusion in metaanalysis on postoperative outcomes (online supplemental appendix 1E), using methods recommended in the Cochrane handbook. ${ }^{26}$

\section{Patient and public involvement}

There was no patient or public involvement in this meta-analysis.

\section{RESULTS}

\section{Literature search}

Following deduplication 807 records were identified from the search strategy (figure 1). Based on screening of titles and abstracts 138 records underwent full-text review. Of these, nine met the inclusion criteria. One additional study was identified by handsearching for the final publication related to a trial protocol found. This study was identified in a non-PubMed indexed peerreviewed journal, which is why it was not identified by our database searches. Both authors agreed this study met the inclusion criteria for this review. Forward citation searches of the ten eligible studies identified one further study for inclusion, in the KoreaMed database. A search of this database identified no other relevant studies. Electronic database search updates in July 2020 identified 175 studies. Following deduplication and screening, one additional study was eligible for inclusion in this review. ${ }^{33}$

A total of 12 identified studies were eligible for this review. $^{28} 293133-41$

\section{Study characteristics and quality}

The characteristics of the 12 included studies are given in tables 1-3 and figure 2. Three studies tested the effects 


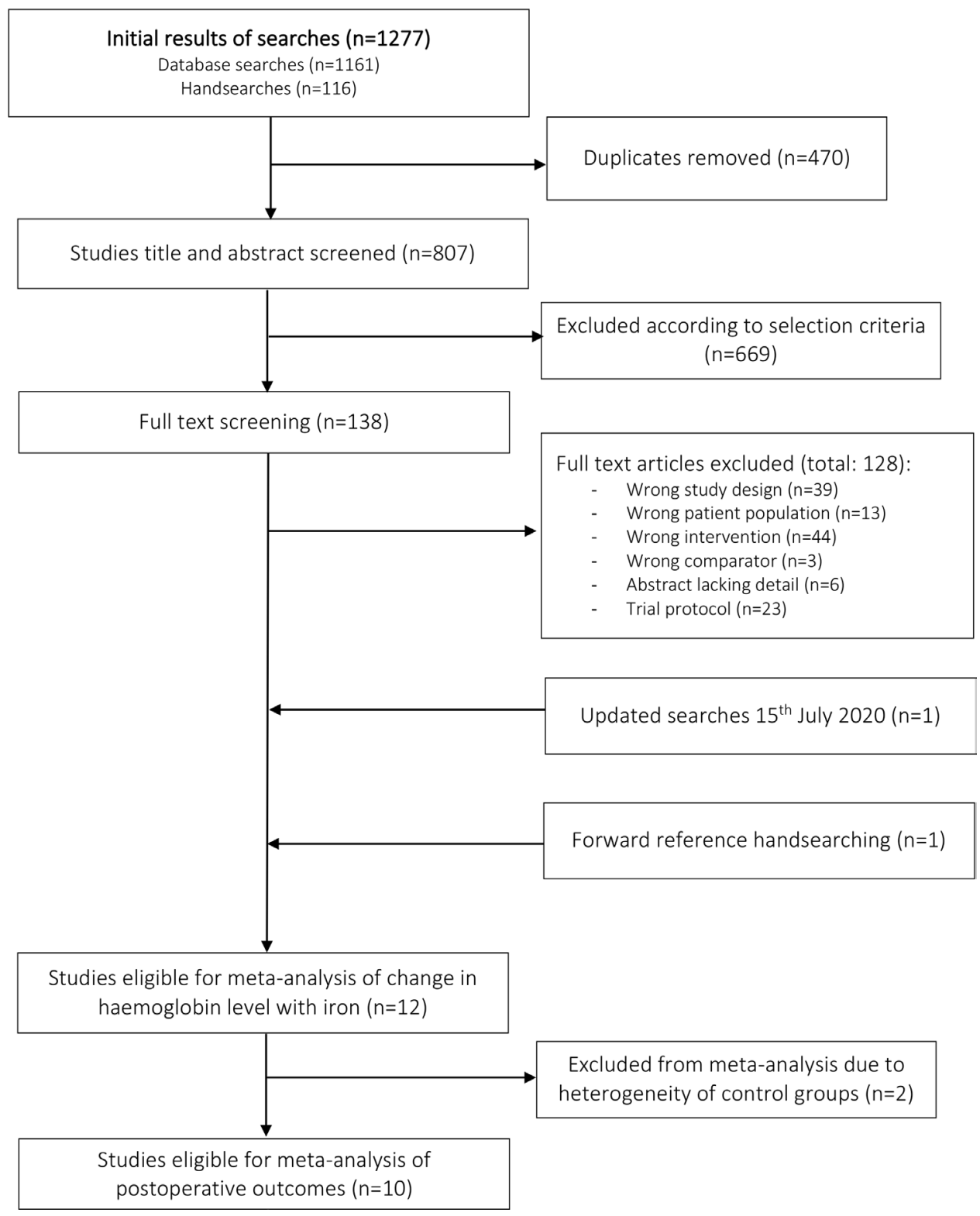

Figure 1 Flow chart of study selection.

of oral iron salts, two of oral sucrosomial iron, four of intravenous iron and three of a combined approach of oral and/or intravenous iron. The average timing of iron treatment before surgery ranged from 2 to 60 days. Intravenous iron was typically given in 1-2 sessions within 4 weeks of surgery, while oral iron was typically given for 4 weeks, a month or more before surgery. Comparators were no preoperative iron (standard care), oral iron or intravenous iron. Eight studies report routine use of restrictive transfusion triggers across all groups, two report using non-restrictive triggers ${ }^{4041}$ and two did not report this. ${ }^{34}{ }^{35}$ Four studies report the 'routine use' of TXA $^{28313338}$; however, only one of these studies formally assess this. ${ }^{33}$ Three studies report that cell salvage was not routinely used..$^{28} 298$ Two studies were excluded from the meta-analysis on postoperative outcomes due to heterogeneity in their control groups. Ten studies included an anaemic control group that received no iron, while in one study two types of IV iron were compared ${ }^{34}$ and another only included a non-anaemic control group. ${ }^{41}$

Of the 10 studies included in the meta-analysis of postoperative outcomes, nine were comparative cohort studies and one a RCT. Nine were full peer-reviewed publications and one a conference abstract, which was later excluded in the sensitivity analysis due to poor quality. ${ }^{35}$ Two studies were in non-English language and required translation by a third (PS, French) and fourth (IHL, Korean) reviewer familiar with systematic review techniques and fluent in the relevant language. For these studies data extraction and quality assessment was performed by the translating reviewer under the guidance of ABS. Detailed guidance of the Newcastle-Ottawa scoring criteria used for this review can be found in table 4 . Of the 10 studies, four were of low quality. ${ }^{33} 353940$ Visual inspection of the funnel plot 


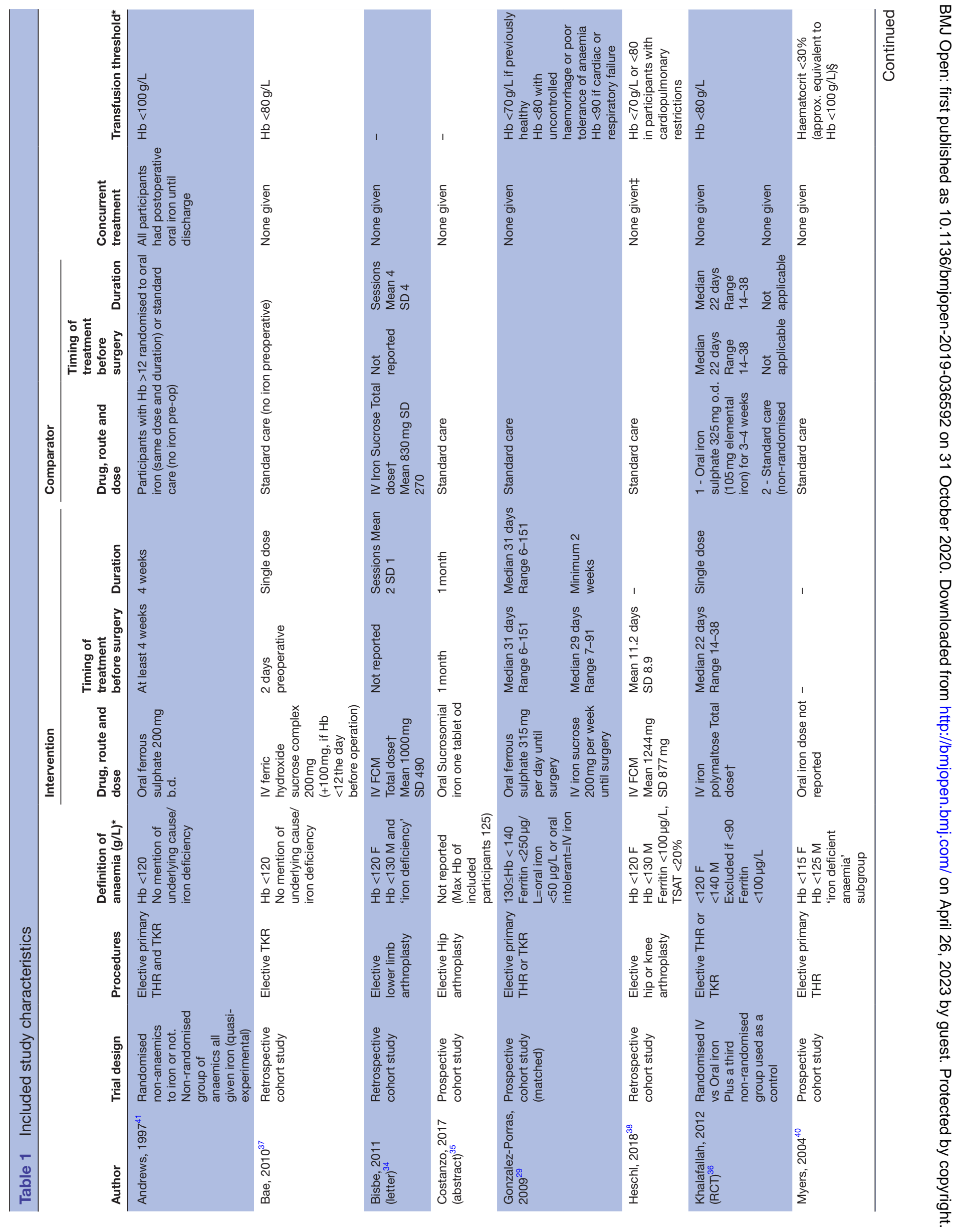




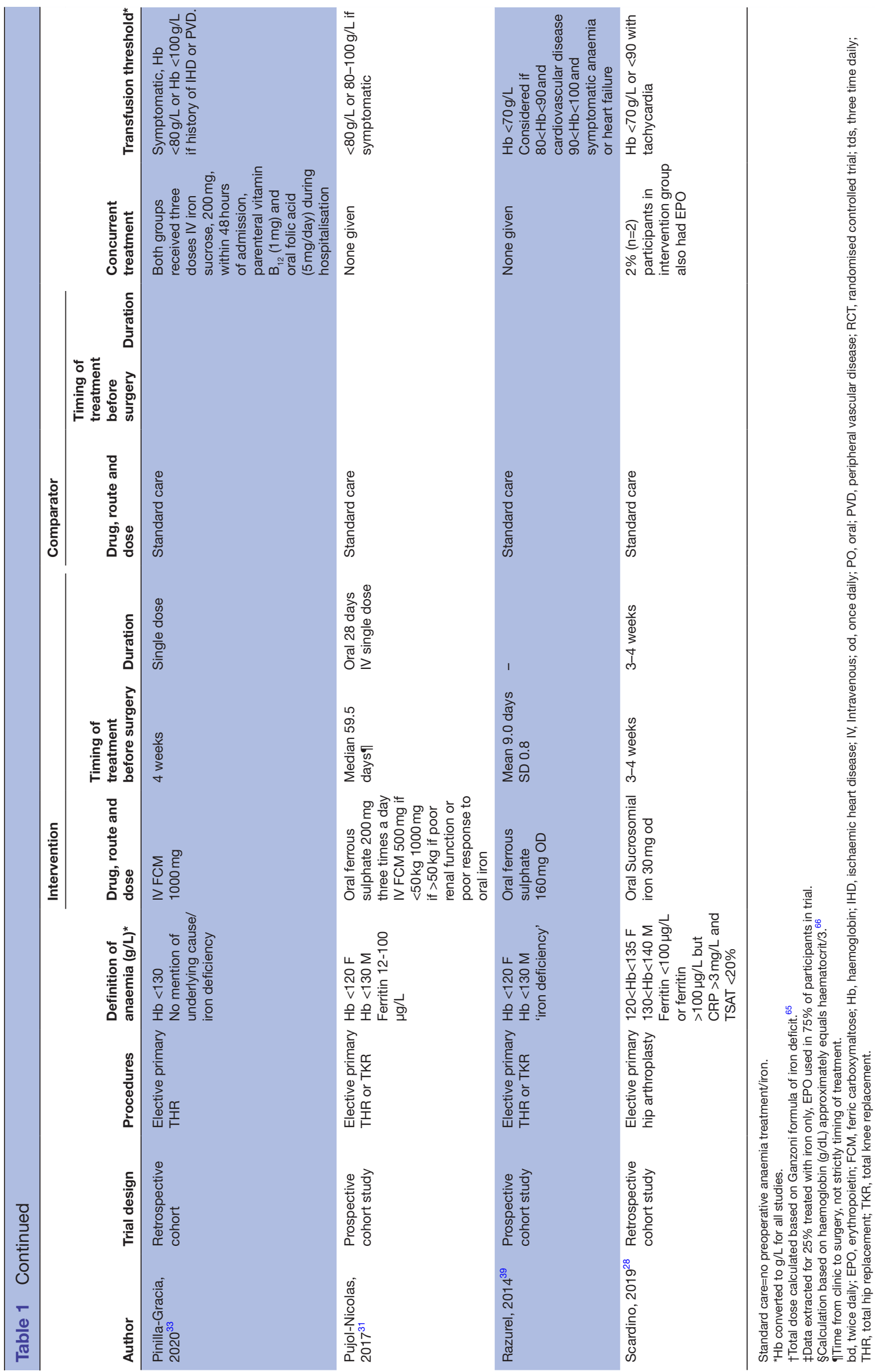

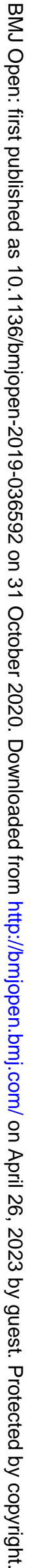




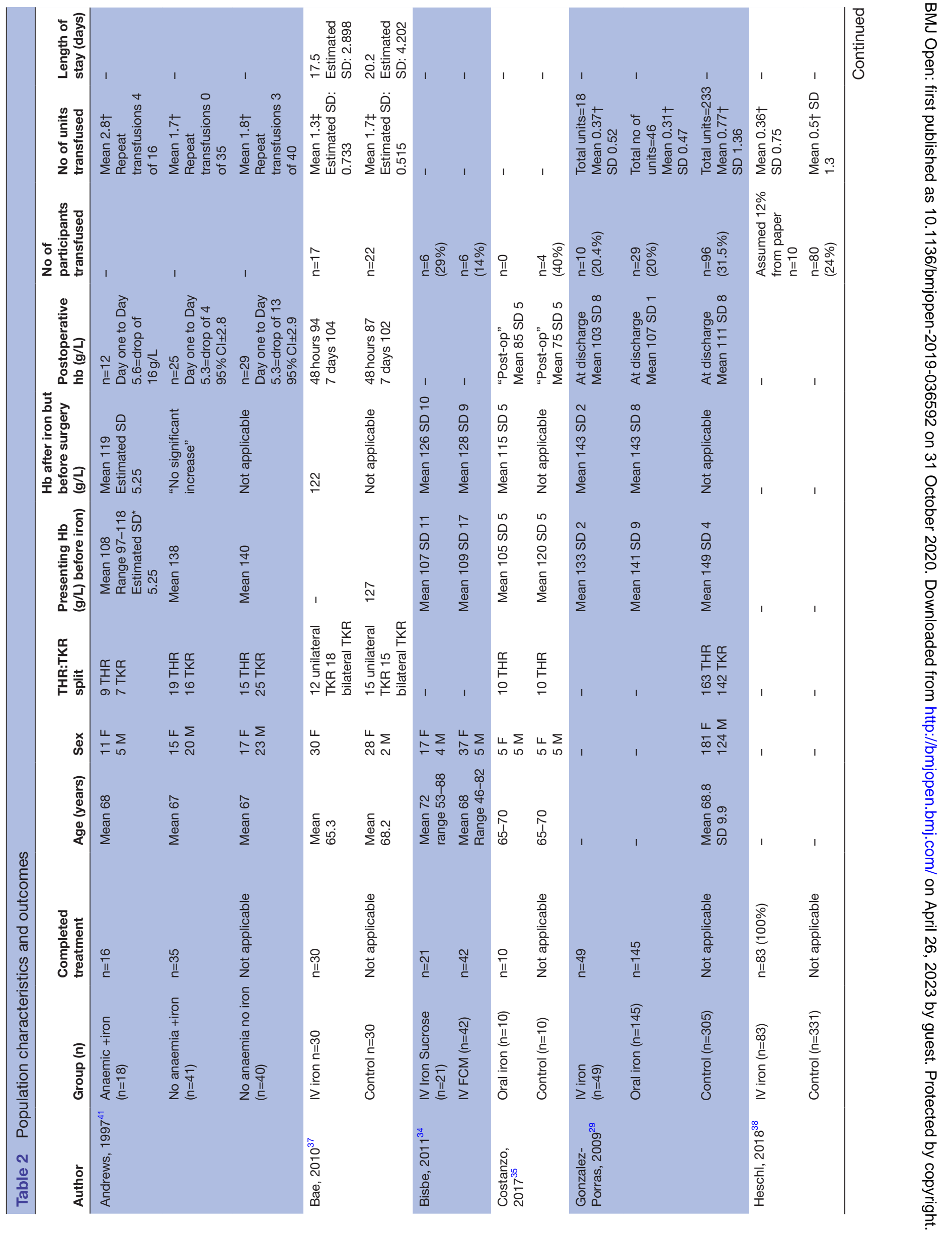




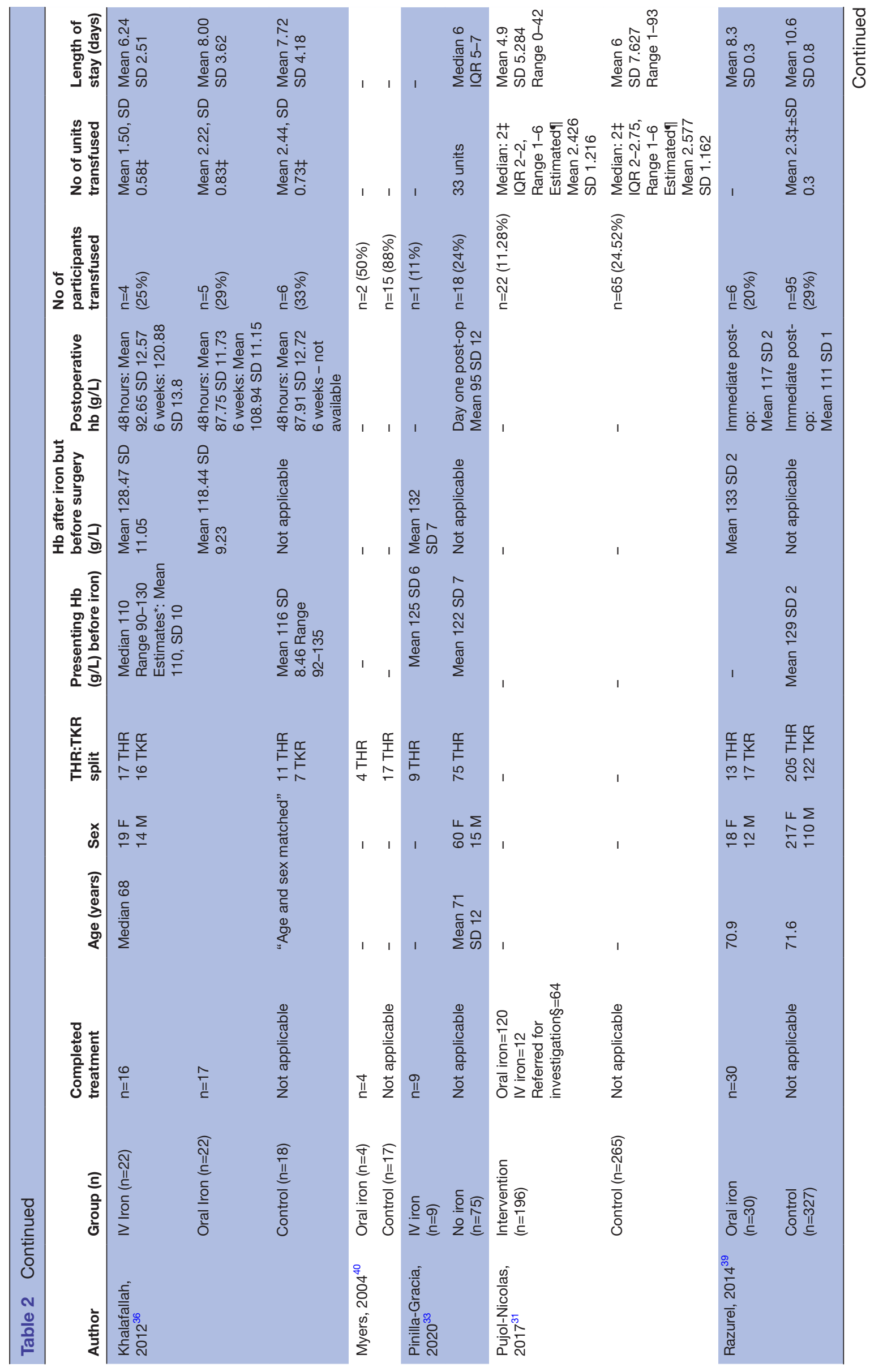

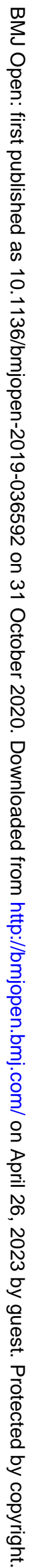




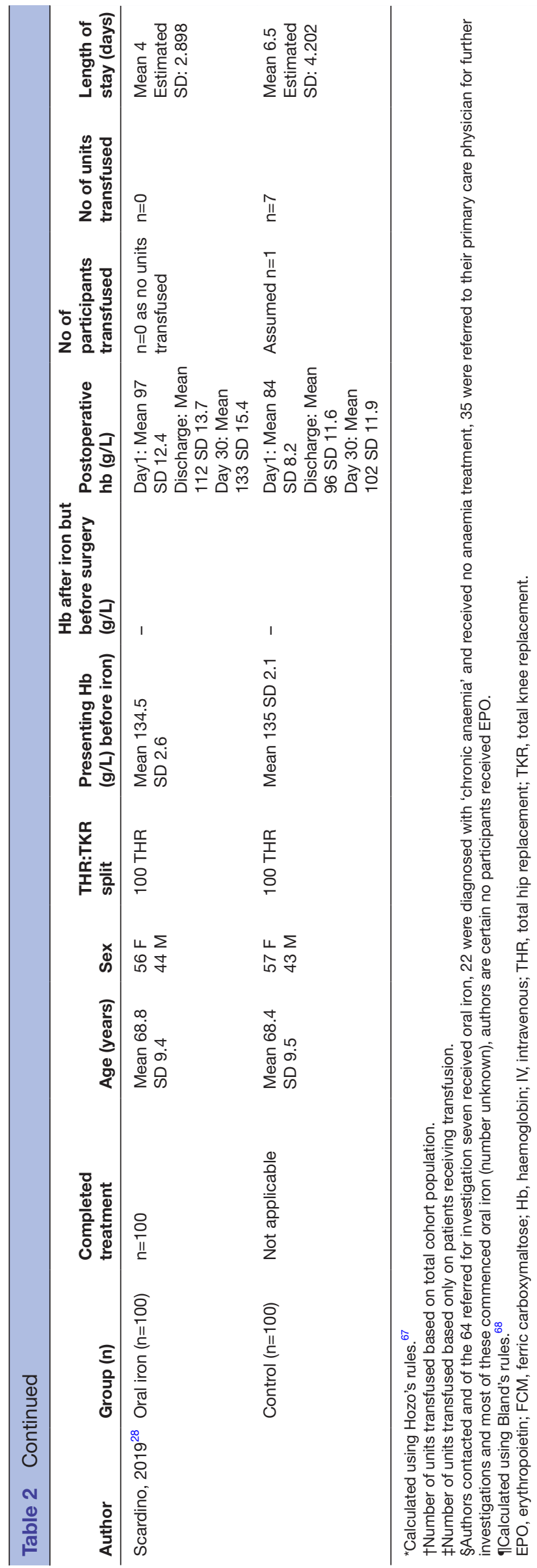

for the primary outcome, perioperative blood transfusion rate, (figure 3) suggests an asymmetrical appearance, with a possible absence of published, smaller studies that show no statistically significant effect. This suggests there may be publication bias towards the positive effects of iron, with the risk that the pooled estimate may be an overestimation of the true intervention effect; however, other explanations cannot be ruled out and the number of studies in the plot just meets the minimum required. ${ }^{26}$

\section{Risk of transfusion}

Eightstudies reported the number of participants receiving perioperative allogenic RBC transfusion with iron treatment compared with no iron treatment. ${ }^{29} 31$ 33 35-37 3940 This outcome was estimated from related data in a further two studies. ${ }^{28}{ }^{38}$ In one of these studies the intervention includes iron $\pm \mathrm{EPO}$, here subgroup data for participants receiving only iron has been extracted. ${ }^{38}$ This paper states that there was no significant difference in the transfusion rate between participants who received iron alone or iron and EPO, so we have estimated the number of participants transfused in the iron only subgroup based on the proportion reported (12\%). In the other study only the number of RBC units transfused has been reported $(n=7) \cdot{ }^{28}$ In order to reduce the risk of inflating the effect size of iron, we have assumed these units have been given to the smallest plausible number of participants $(n=1)$.

Ten studies ( $\mathrm{n}=2178$ participants $)$ were pooled (figure 4). The transfusion rate in the iron groups combined was $15.1 \%(106 / 700)$ compared with $27.2 \%$ in the control group (402/1478). Treating anaemic participants with iron before THR or TKR significantly reduces the risk of receiving a perioperative blood transfusion by $39 \%$ (RR $0.61,95 \%$ CI 0.50 to $0.73, \mathrm{p}<0.0001$ ). There was no evidence of heterogeneity $\left(\mathrm{I}^{2}=0 \%\right)$, there were no significant subgroup differences $(\mathrm{p}=0.35)$.

Sensitivity analyses excluding studies where the underlying cause of anaemia was not reported as iron deficiency, ${ }^{33} 35$ low-quality studies, ${ }^{33} 353940$ studies with any estimated values, ${ }^{28} 38$ studies using concurrent EPO, ${ }^{28}$ studies with a presenting $\mathrm{Hb}>130 \mathrm{~g} / \mathrm{L},{ }^{28}{ }^{29}$ or all of the above, had no discernible effect on the effect size estimate (see online supplemental appendix 1F).

\section{Number of RBC units transfused}

Five studies ( $n=1496$ participants) report the number of RBC units transfused, ${ }^{29} 3136-38$ three of these required conversion to population level statistics. ${ }^{31} 3637$

There was an average reduction of $0.37 \mathrm{RBC}$ units $(95 \%$ CI -0.47 to $-0.27, \mathrm{p}<0.001)$ transfused per anaemic patient undergoing elective THR or TKR in the preoperative iron group compared with control (figure 5). Heterogeneity was low $\left(I^{2}=40 \%\right)$ and there were no significant subgroup differences $(\mathrm{p}=0.06)$.

None of these studies were of low quality or used a concurrent treatment, all studies report the cause of anaemia as being iron deficiency. Sensitivity analyses excluding studies where the variance had been 


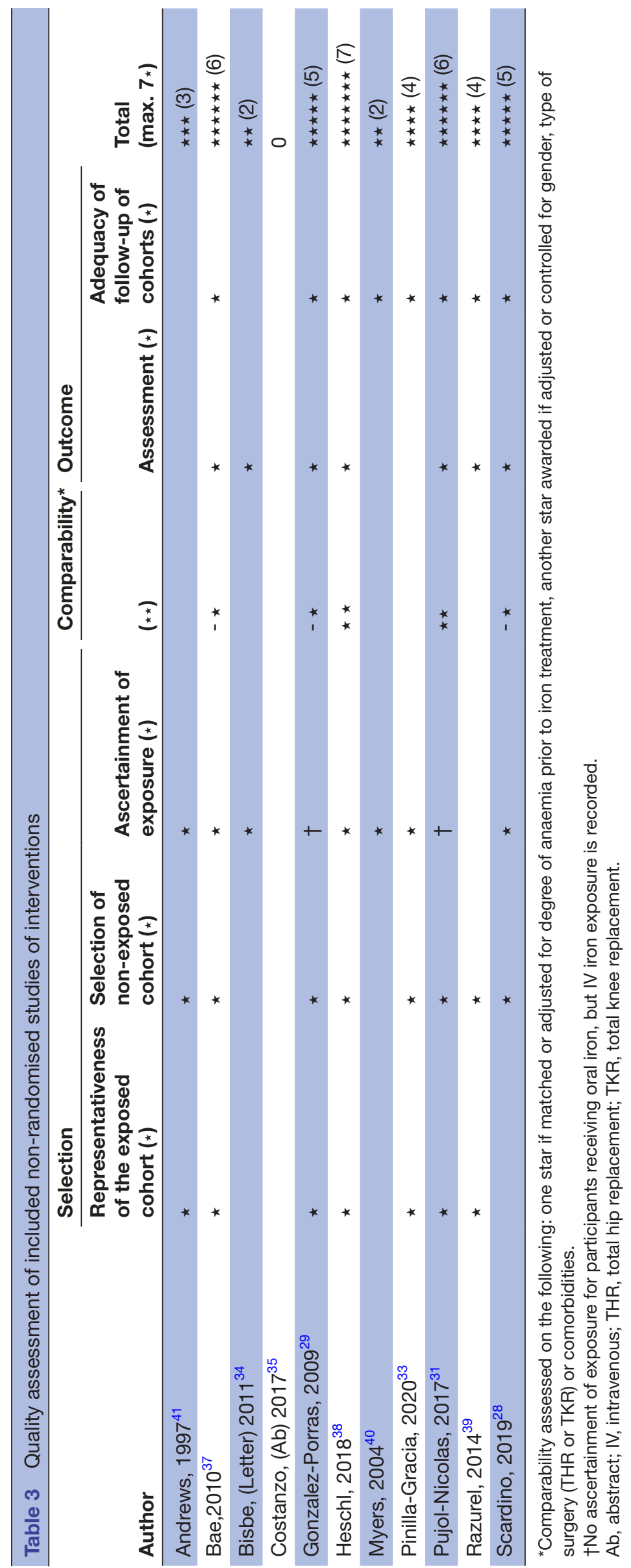

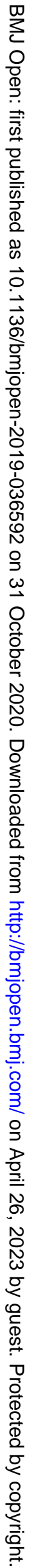




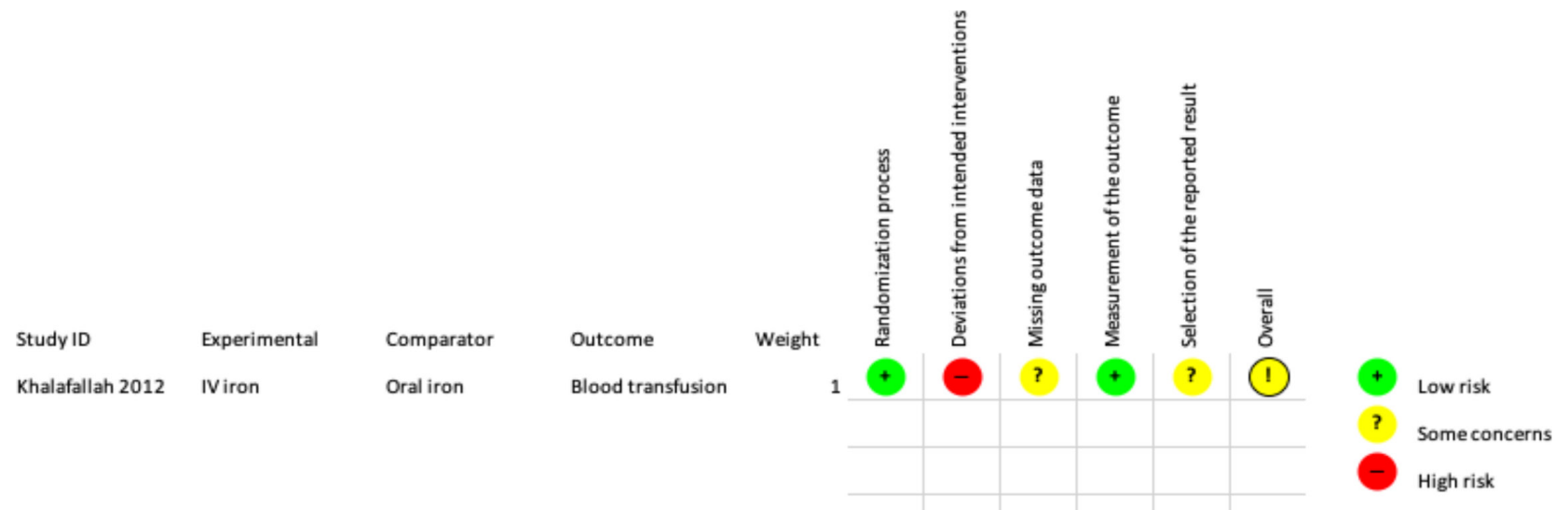

Figure 2 Quality assessment of the included randomised controlled trial. IV, intravenous.

estimated, ${ }^{37}$ data required conversion to the mean, ${ }^{31}$ with a presenting $\mathrm{Hb}>130 \mathrm{~g} / \mathrm{L},{ }^{29}$ or all of the above, had no discernible effect on the effect size estimate (online supplemental appendix 1).

\section{Length of hospital stay}

Five studies ( $n=1140$ participants) report mean LoS but two do not report any measure of variance, or other statistics that would allow this to be calculated..$^{28}{ }^{37}$ In line with Cochrane recommendations the mean of the SDs from the three other studies was used for these studies. ${ }^{26}$

The combined mean LoS in the no iron group was 8.72 days (SD 4.97) and in the iron group was 6.12 days (SD 4.19). LoS was reduced by an average of 2.08 days in the preoperative iron group compared with no iron $(95 \% \mathrm{CI}$ -2.64 to $-1.51, \mathrm{p}<0.001$ ) (figure 6 ). Low heterogeneity
$\left(\mathrm{I}^{2}=40 \%\right)$ and no significant subgroup differences were observed $(\mathrm{p}=0.09)$.

All of the studies report the cause of anaemia as iron deficiency. When studies of low quality, ${ }^{39}$ with an estimated SD, ${ }^{28}{ }^{37}$ using a concurrent treatment, ${ }^{28}$ or with a presenting $\mathrm{Hb}>130 \mathrm{~g} / \mathrm{L}^{28}$ were excluded a significant effect in favour of iron remains. When all exclusions are applied only two studies remain, reducing the power of pooled estimates. ${ }^{3136}$ A beneficial effect of iron persists (MD -0.98 days), but the $95 \%$ CI is much wider (-2.02 to 0.05 days, $\mathrm{p}=0.06, \mathrm{I}^{2}=0 \%$, online supplemental appendix $1 \mathrm{~F})$.

\section{Change in $\mathrm{Hb}$ concentration}

Six studies ( $n=325$ participants) report average Hb concentrations pre- and post-iron treatment. ${ }^{29} 33-3641$ Two studies

Table 4 Definitions used with the Newcastle-Ottawa scale to assess quality of non-randomised studies of interventions in this review

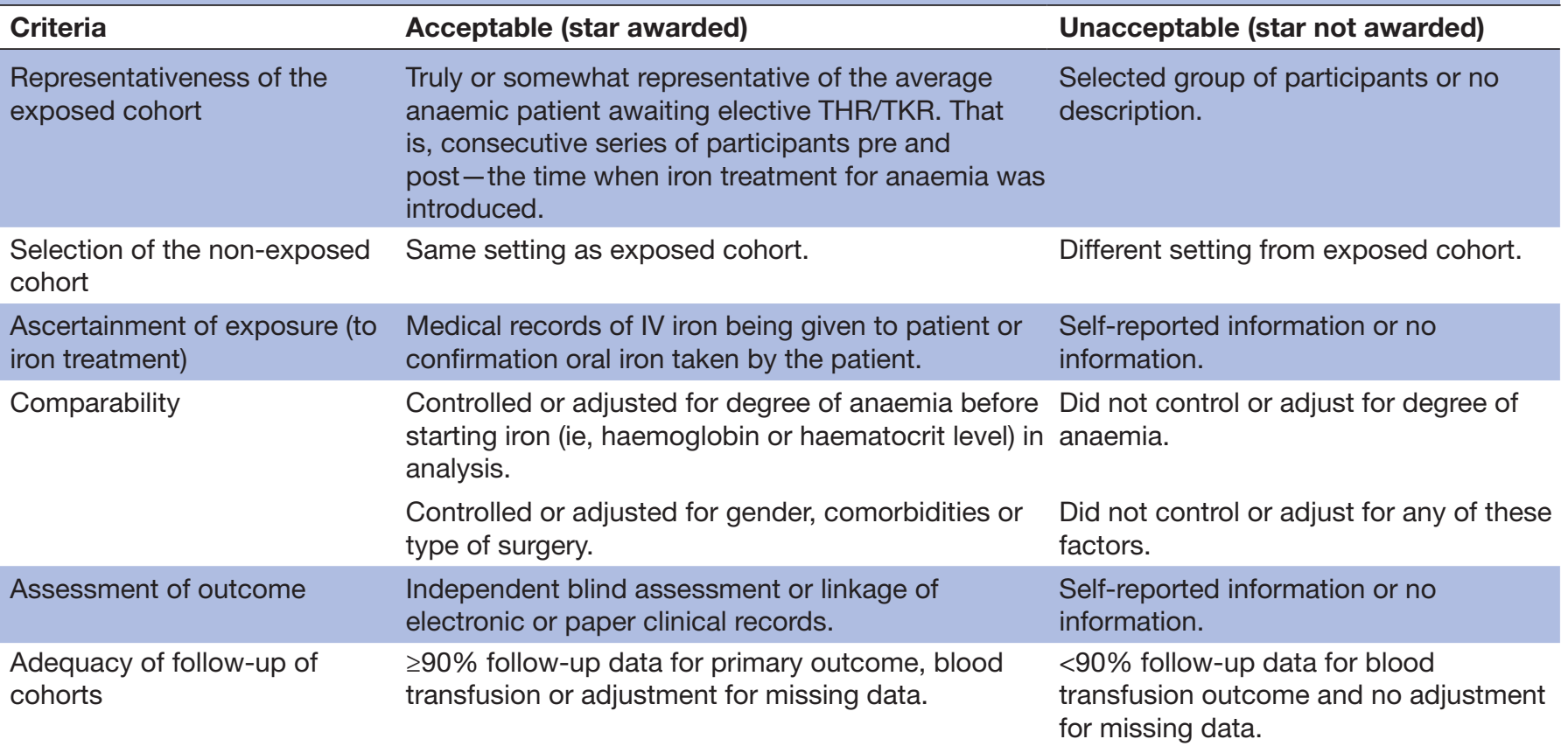

IV, intravenous; THR, total hip replacement; TKR, total knee replacement. 


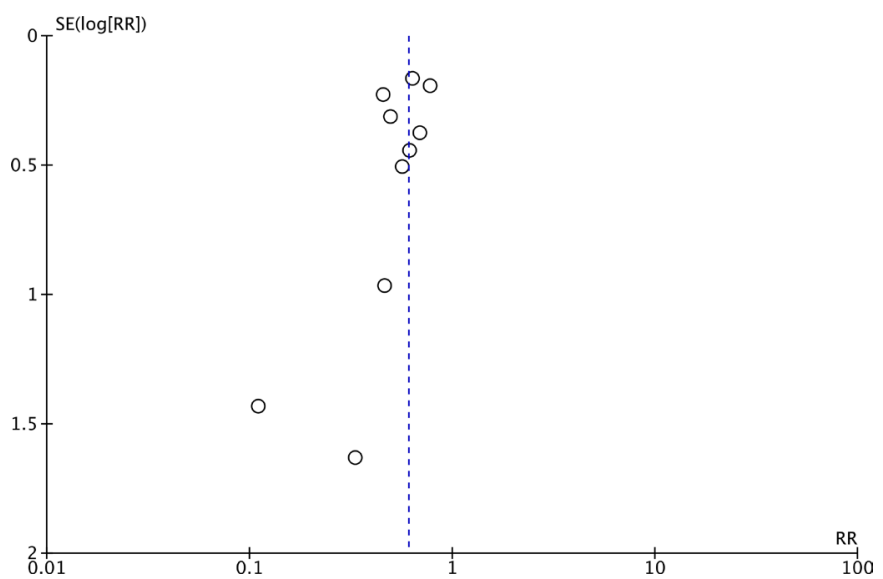

Figure 3 Funnel plot for primary outcome, perioperative blood transfusion rate. $\mathrm{RR}$, risk ratio.

combined oral or intravenous iron as the intervention, ${ }^{29} 36$ one used oral iron salts, ${ }^{41}$ one used intravenous iron only, ${ }^{33}$ one compared two intravenous iron formulations ${ }^{34}$ and one used sucrosomial iron. ${ }^{35}$ The duration of treatment, and hence time between $\mathrm{Hb}$ measurements, was reported in five 2933353641 of the six studies. The average time was 28 days. However, often this was not accurately reported, and where reported there was often a wide range of timings.

Iron was associated with a significant increase in mean $\mathrm{Hb}$ concentration (MD $11.48 \mathrm{~g} / \mathrm{L}, 95 \%$ CI 8.12 to $14.83 \mathrm{~g} / \mathrm{L}$,figure 7 ) .

In an exploratory analysis, a higher presenting $\mathrm{Hb}$ was associated with less of a $\mathrm{Hb}$ increase following iron treatment (figure 8 , slope of the regression line $-0.30,95 \%$ CI -0.59 to $-0.19, \mathrm{p}=0.04$ ) and oral iron was associated with less of a $\mathrm{Hb}$ increase compared with intravenous iron (figure 9 , slope of the regression line $7.50 \mathrm{~g} / \mathrm{L}, 95 \% \mathrm{CI}$ -2.24 to $17.24 \mathrm{~g} / \mathrm{L}, \mathrm{p}=0.11$ ).

$\mathrm{Hb}$ concentrations after surgery were rarely reported, and where reported significant heterogeneity in timing was seen, therefore pooling studies in a meta-analysis was considered inappropriate. One study reported no difference $^{36}$ with iron while two studies showed beneficial effects of preoperative iron on postoperative Hb. ${ }^{28} 37$

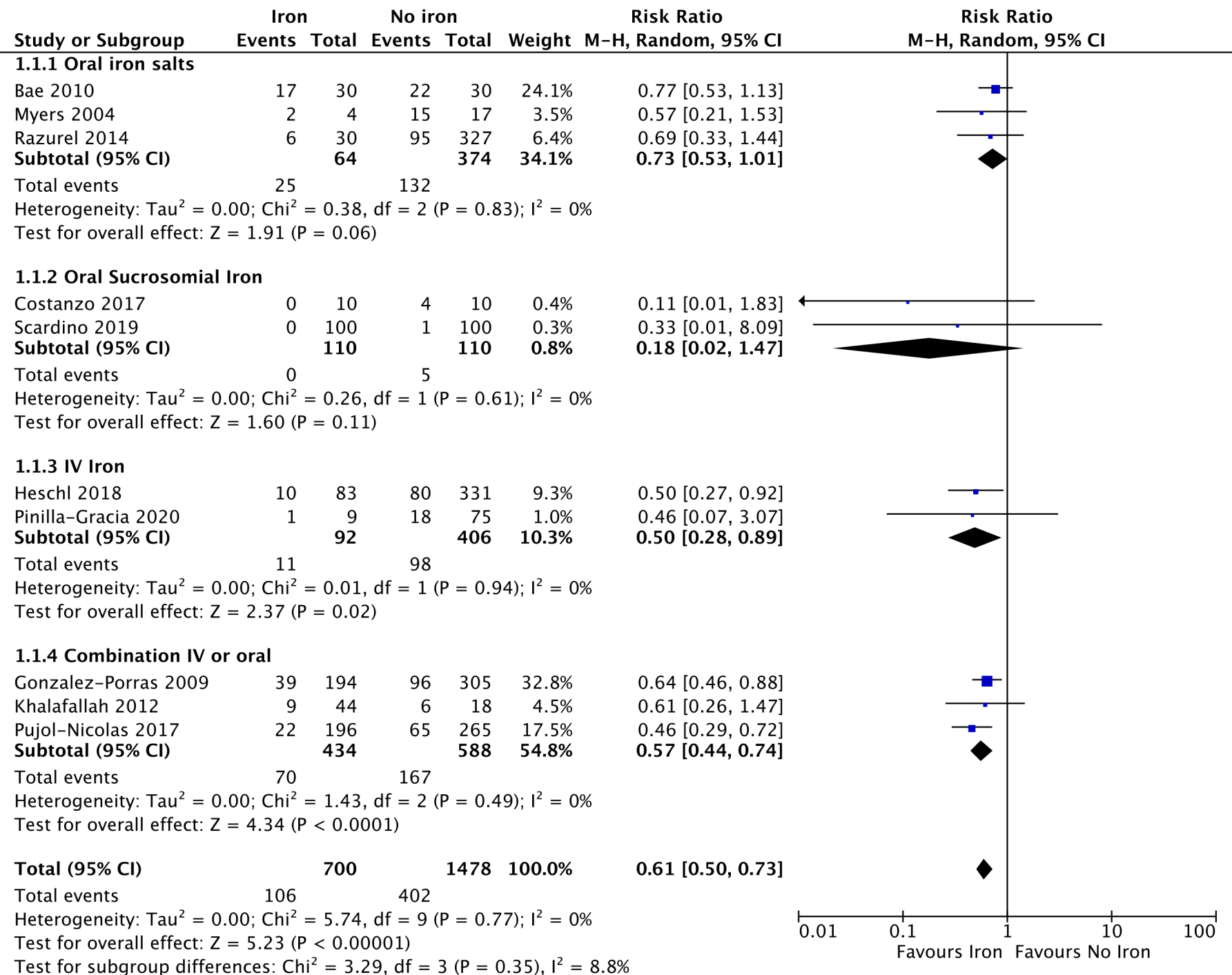

Figure 4 Forest plot comparing number of anaemic participants transfused in those receiving preoperative iron to no iron. IV, intravenous. 


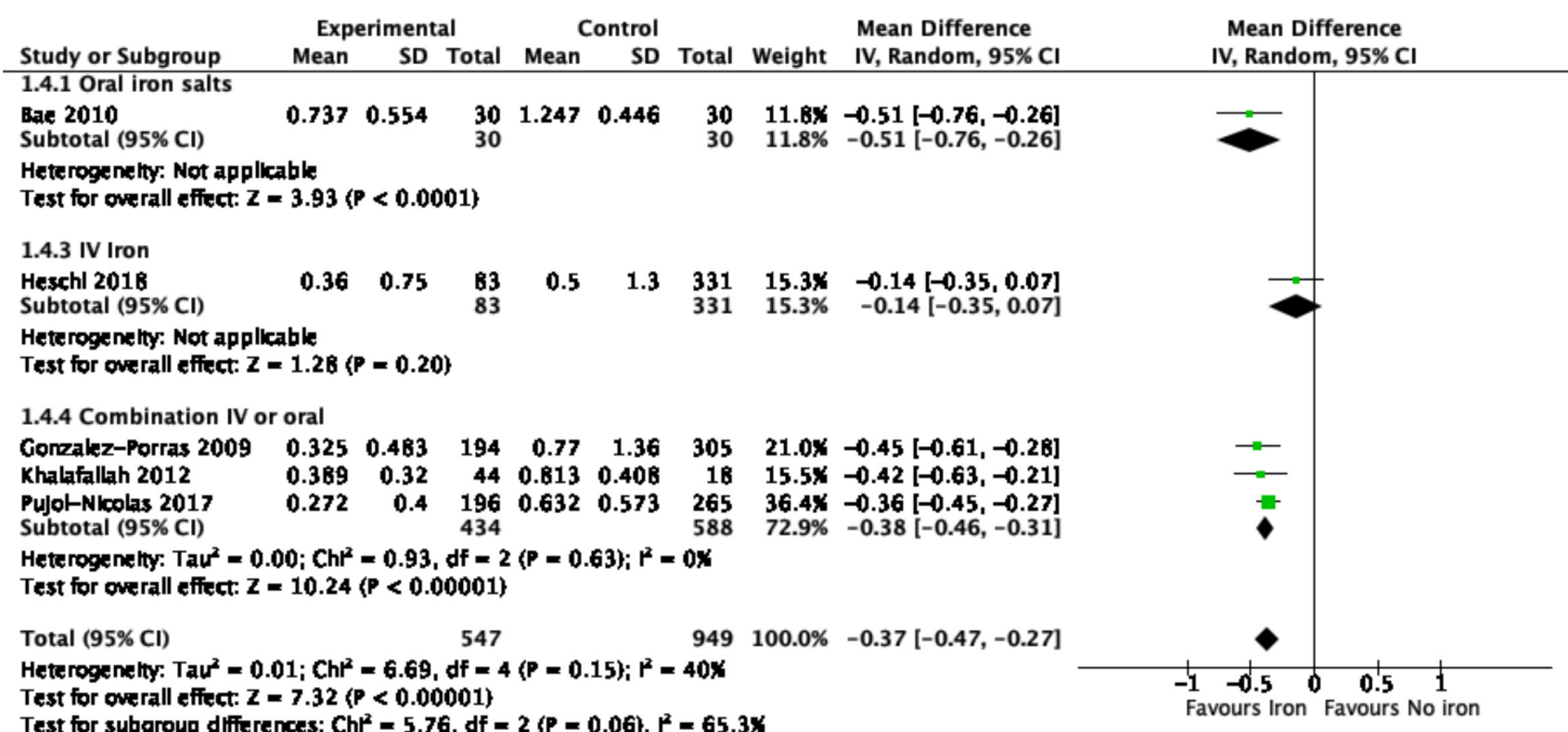

Figure 5 Forest plot of units of blood transfused with outcome standardised to units per patient undergoing surgery. IV, intravenous.

Other outcomes

Three studies report some cost estimates, all favour iron. Savings estimates include $\$$ A400 000 per year (2012) for a 300 bed hospital with intravenous iron, ${ }^{36} € 1763.25$ (2019) per patient with sucrosomial iron $^{28}$ and $£ 162.46$ (2017) per patient with a combined oral or intravenous iron approach. ${ }^{31}$

Other outcomes such as infection, medical complications and readmissions were rarely reported and, where they were, no differences were reported. Four studies (n=167 participants, 94 IV iron, 73 oral) report adverse events. ${ }^{33} 343641$ Four participants $(4 \%)$ in the intravenous and three participants (4\%) in the oral iron groups report minor complications. One study reported a significantly reduced critical care admission rate favouring iron (control $4.9 \%$ vs intervention $0.5 \%, \mathrm{p}=0.007) .{ }^{31}$ Another reports improved QoL outcomes with IV vs oral iron ${ }^{36}$ using a modified short-form 36 questionnaire, however, there were concerns acknowledged by the study authors around these data and confounders.

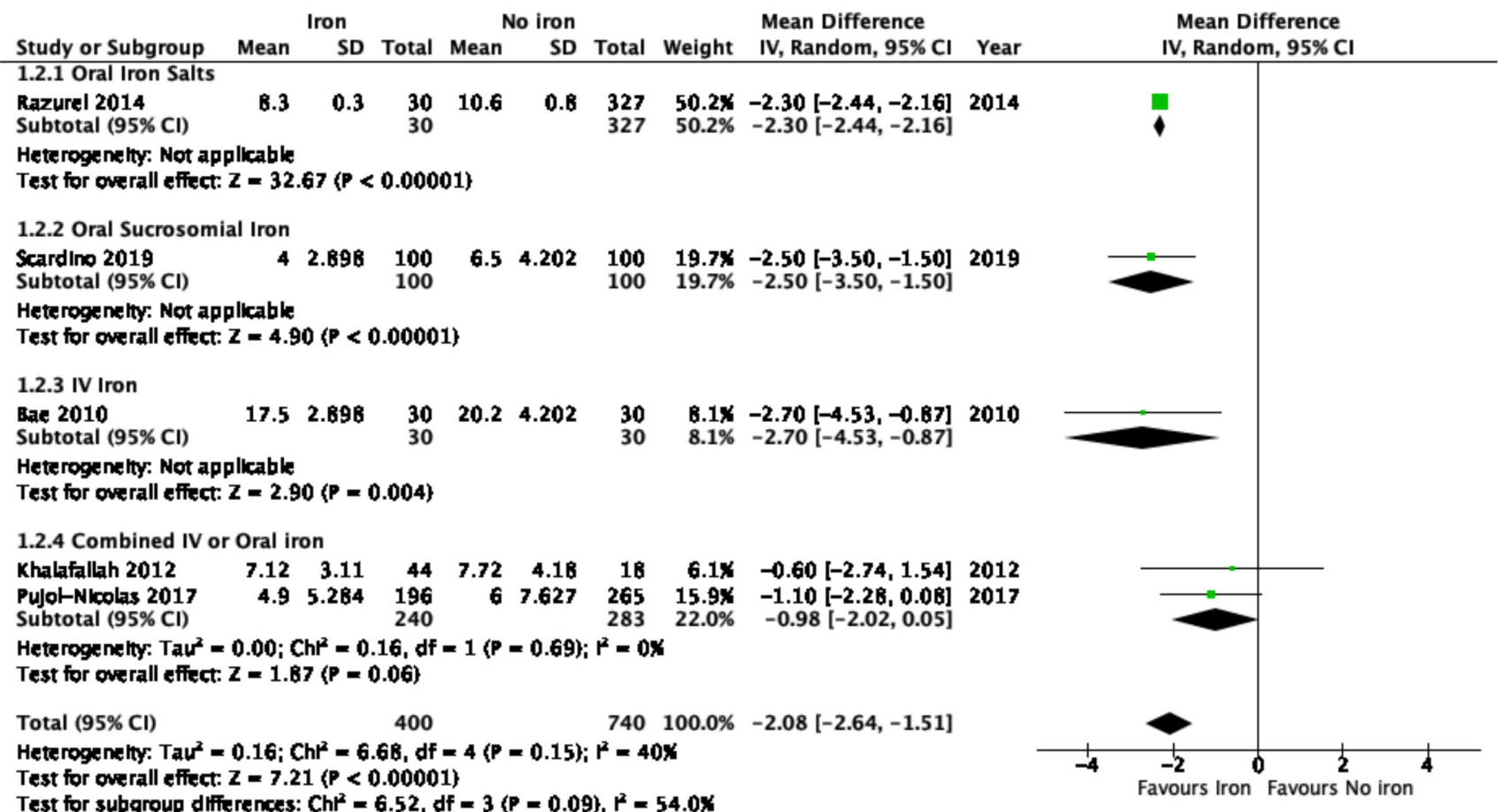

Figure 6 Forest plot comparing the length of stay of in anaemic participants receiving preoperative iron or no iron. IV, intravenous. 


\section{Study name Subgroup within study}

Statistics for each study

$\begin{array}{cc}\text { Difference } & \text { Standard } \\ \text { in means } & \text { error }\end{array}$

\begin{tabular}{|c|c|}
\hline Bisbe IV IS & IV \\
\hline Bisbe IV FCM & IV \\
\hline \multicolumn{2}{|c|}{ Gonzalez-PorrasIV } \\
\hline Khalafallah & IV \\
\hline Pinilla-Gracia & IV \\
\hline \multicolumn{2}{|c|}{ Gonzalez-PorrasOral } \\
\hline Khalafallah & Oral \\
\hline Andrews & Oral \\
\hline Costanzo & Sucrosomi \\
\hline
\end{tabular}

19.000

19.000

10.000

18.470

7.000

2.000

8.440

11.000

10.000

11.477

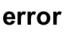

1.786

1.926

0.221

2.052

1.706

0.666

2.194

1.231

1.483

1.712
Difference in means and $95 \% \mathrm{Cl}$

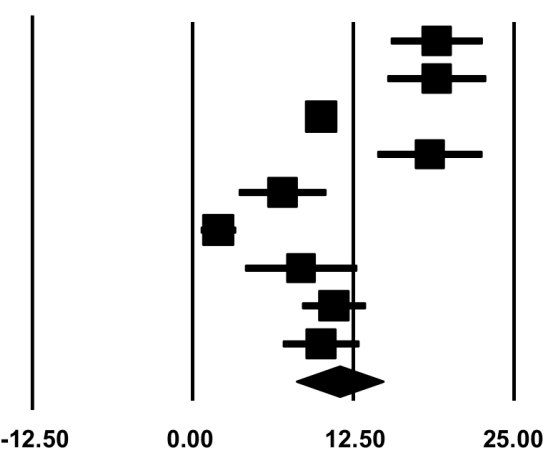

Figure 7 Forest plot of change in $\mathrm{Hb}$ pre-iron to post-iron accounting for correlation between result. FCM, Ferric Carboxymaltose; Hb, haemoglobin; IV, intravenous.

\section{DISCUSSION}

Preoperative anaemia is common in patients undergoing elective THR or TKR and is associated with poorer postoperative outcomes and increased transfusion rates. This review has shown that the use of preoperative iron in anaemic participants is associated with a reduction in the number of participants requiring perioperative transfusion, the number of units transfused and LoS. The presenting $\mathrm{Hb}$ concentration and type of iron used appear to correlate with the degree of $\mathrm{Hb}$ increase, but insufficient data were available to examine correlation with postoperative outcomes.

However, the results should be interpreted with caution as only one of the included studies was an RCT at risk of bias. The analyses and meta-regression are, therefore, effectively observational and may exaggerate the true treatment effect. Higher quality evidence, such as a well conducted, adequately powered RCT is required to inform future clinical practice or policy change. A future RCT in this field could consider three treatment arms; no iron, oral iron and intravenous iron, and could include

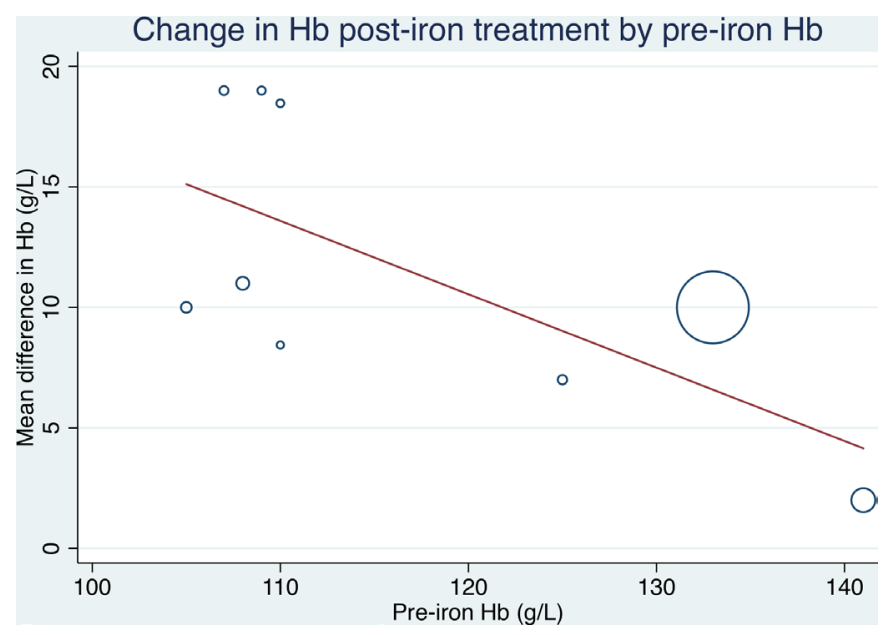

Figure 8 L'Abbe plot showing change in $\mathrm{Hb}$ from pre-iron to post-iron treatment by presenting $\mathrm{Hb}$ level. Each circle represents a group treated with one type of iron, some studies have two circles. Size relates to precision of estimate. $\mathrm{Hb}$, haemoglobin. clinical, economic and QoL outcomes. Although, in the setting of existing guidelines, a no iron control group may prove difficult to implement and should be carefully considered.

Our results are in keeping with previous systematic reviews on preoperative anaemia optimisation in orthopaedic ${ }^{42-45}$ and other surgical populations. ${ }^{46-49}$ However, this is the first review to include NRSIs and focus solely on the use of preoperative iron in elective arthroplasty patients, as a means of patient optimisation before surgery. This group of patients have been described as one of the most appropriate for preoperative anaemia optimisation, due to the prevalence of iron deficiency anaemia and typical time available for anaemia optimisation on elective surgery pathways. ${ }^{8}$ Unlike other reviews, we have intentionally not included studies that include arthroplasty following trauma as the time available for preoperative optimisation with iron is minimal and this population is typically older, with more comorbidities and are more likely to encounter postoperative complications than elective arthroplasty patients. ${ }^{50}$

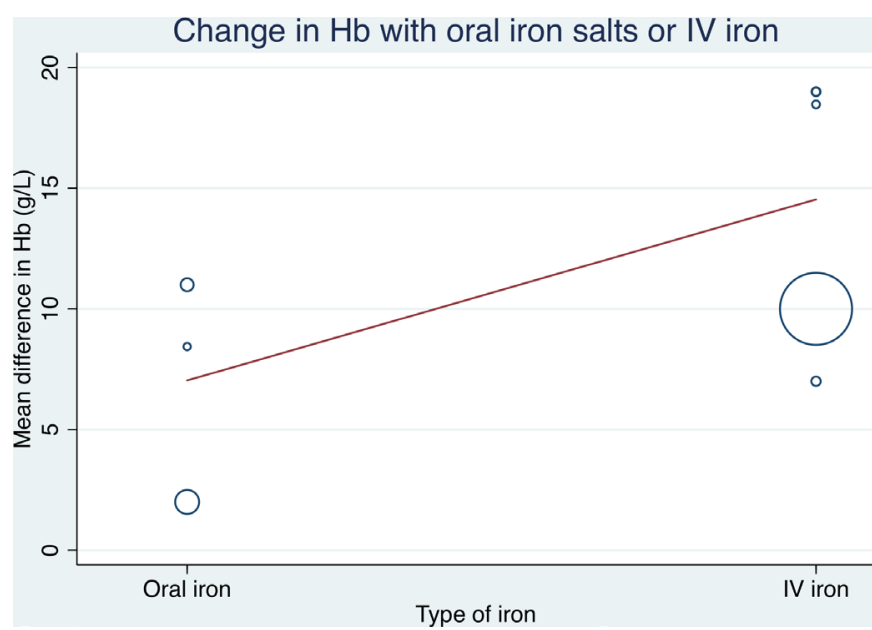

Figure 9 L'Abbe plot showing change in $\mathrm{Hb}$ by oral or intravenous iron (excludes sucrosomial iron as only one study used this and reported pre-iron and post-iron $\mathrm{Hb}$ data). $\mathrm{Hb}$, haemoglobin; IV, intravenous. 
Our results are also similar to those seen in metaanalyses on other PBM interventions such as the use of restrictive transfusion triggers, which have been estimated to reduce the risk of blood transfusion by $43 \%$ across a range of clinical specialties, ${ }^{51}$ and TXA, which has been estimated to reduce the risk of blood transfusion in surgical patients by $38 \% .^{52}$ However, it should be noted the quality of evidence for reduced transfusion triggers and TXA is much stronger as their estimated effect sizes are based on 31 and 129 randomised trials, respectively.

\section{Treatment options}

National and international guidelines recommend that treatment for preoperative anaemia is directed by the underlying cause. ${ }^{10}{ }^{12}$ For the majority of patients undergoing elective THR or TKR this is likely to be iron deficiency (functional of absolute) which would be expected to respond to iron. ${ }^{23}$ However, this will not always be the cause. Algorithms for diagnosis and management of perioperative anaemia have been proposed, but the effectiveness of these is beyond the scope of this review. ${ }^{12}$ Three studies in this review appeared to give iron without assessing the underlying cause of anaemia. All three showed a beneficial effect of iron, possibly because iron was used in the setting of iron deficiency, but this was not clearly reported, or because only a minority of patients had anaemia of another cause.

Three studies in this review used a predefined decisionmaking algorithm to determine preoperative anaemia treatment. ${ }^{29} 3138$ This approach seems logical given there may be a different underlying cause of preoperative anaemia, differing tolerance to oral iron and variations in timing of screening in relation to surgery. This approach is also in keeping with international guidance. ${ }^{12}$ One study included a 'safety-net' of referral for further investigation if the $\mathrm{Hb}$ and/or ferritin levels were considered too low, ${ }^{31}$ in keeping with guidance from the British Society of Gastroenterology. ${ }^{53}$

As identified in this review there are different iron treatments available including oral iron salts, oral sucrosomial iron and intravenous iron preparations. While this review lacks high quality RCTs, which might allow us to recommend an optimum treatment modality, our exploratory analysis suggests intravenous iron correlates with a greater $\mathrm{Hb}$ increase than oral iron. However, no significant subgroup differences between iron preparations were seen for postoperative outcomes, although this analysis may have been underpowered and was not a randomised comparison between modes of delivery.

Debate continues around the optimal dose and administration technique for oral iron salts, to maximise absorption and reduce side effects. Recent recommendations involve lower daily or alternate day doses $(40-100 \mathrm{mg}$ elemental iron) along with specific administration advice $^{54}$; newer phospholipid bound sucrosomial iron formulations offer a potential oral alternative. Highquality RCTs comparing the effectiveness of different dosing regimens, or testing newer oral iron preparations are required to direct future clinical practice. ${ }^{55}$

Concerns around the safety of intravenous iron exist based largely on the risks of anaphylaxis seen with older preparations. A network meta-analysis found them to be safe and effective at increasing $\mathrm{Hb}$ concentrations in anaemic and non-anaemic iron deficient participants, across a range of medical specialties ${ }^{56}$ However, even with newer intravenous iron preparations further work may be needed to identify the optimum formulation. Bisbe et $a p^{34}$ compared intravenous iron sucrose with intravenous ferric carboxymaltose, and found they produced a comparable $\mathrm{Hb}$ response, but participants receiving intravenous ferric carboxymaltose required fewer treatment sessions to receive their total iron dose (mean 4 sessions vs 2 sessions, $\mathrm{p}<0.001)$. This is likely to be attractive to patients, clinicians and policy-makers, so an intravenous iron preparation that allows a total dose infusion may warrant further investigation.

\section{Timing}

There was considerable variability in the timing of commencing iron treatment before surgery. A recent international consensus statement on the management of perioperative anaemia and iron-deficiency recommends oral iron be given for $6-8$ weeks prior to surgery and IV iron used if surgery is planned within 6 weeks. ${ }^{12}$ However, work by Muñoz et al found that even very short-term perioperative intravenous iron, given either 2-5 days preoperatively and/or 2-3 days postoperatively, significantly reduced transfusion rates and length of stay. ${ }^{57}$ Where oral iron was used in the studies included in this review it was typically for less than the 6-8 weeks recommended, which may be limiting the beneficial effects of oral iron seen.

\section{Definition of anaemia}

Two studies included participants with a presenting $\mathrm{Hb}$ greater than $130 \mathrm{~g} / \mathrm{L}$ (tables 1 and 2) ${ }^{28}{ }^{29}$ reported a beneficial effect of iron on postoperative outcomes (number of participants and units transfused and LoS). This may support the opinion that gender-specific definitions of preoperative anaemia are not appropriate, and might even suggest $\mathrm{Hb}$ thresholds of $130 \mathrm{~g} / \mathrm{L}$ are too low. ${ }^{12} 1320$

\section{Strengths and limitations}

Our review methodology followed a preregistered protocol and is reported in line with Preferred Reporting Items for Systematic Reviews and Meta-Analyses guidance. ${ }^{26}{ }^{58}$ However, as with any meta-analysis, this review is limited by the included studies and despite our efforts it is possible some studies may have been missed. Comprehensive searching techniques were used and NRSI designs with a control group were included. Handsearching identified four additional studies, not found in the database searches. ${ }^{29} 343637$ This initially raised concerns and prompted a review of the search strategy, but no major issues were identified. When looking closer 
at the source of these four studies it became clear that the database searches would not have been expected to identify them. Our comprehensive searches identified two non-English language studies. Despite our extensive searches, which included the grey literature to reduce the risk of publication bias, a funnel plot suggests there may be evidence of publication bias, though there were only ten studies and other explanations cannot be excluded.

Observational study designs and studies with low event rates, as seen in most studies in this review, are at higher risk of bias and may exaggerate treatment effects compared with well conducted, adequately powered RCTs. ${ }^{59}$ Although measures have been taken to explore the impact of low quality studies in our sensitivity analysis, the sparse data seen in many of the included studies, and the lack of any high quality RCTs in this review does limit the reliability of our results and the conclusions that can be drawn from them. ${ }^{60}$ Ideally RCTs and NRSIs would have been pooled separately due to differential risk of bias; however, given there was only a single small RCT we pooled this with the NRSIs.

Differences in how data on the quantity of blood transfused are reported, meant calculations to standardise these were required. Further work to define a standard definition for reporting, which would aid interpretation and data pooling, may be warranted.

Few studies measured patient adherence for those assigned to receive oral iron. It is well documented that adherence to oral iron salts can be an issue.$^{61}$ There was also considerable variation in the timing and duration of treatments even within studies, with one giving oral iron for between 6 and 151 days. Given it would be expected to take 2-4 weeks to see a $\mathrm{Hb}$ response to oral iron, 6 days is almost certainly too short for any meaningful effect to take place. ${ }^{62}$ Both of these limitations may underestimate the true treatment effects of iron, yet despite this, significant clinical benefits are seen in this meta-analysis. In several studies there was little adjustment for confounders which may impact on a patient's risk of receiving a blood transfusion notably presenting $\mathrm{Hb}$ concentration or cardiorespiratory comorbidities, which were often used to trigger blood transfusion. In addition, the use of other PBM interventions in routine use was poorly reported across the included studies, with most not reporting on these at all. Where they were, this was typically not quantified and only referred to as being in 'routine practice'. These potential confounders were therefore typically not well controlled or adjusted for across studies. This review also included studies where a treatment in addition to iron was given for up to $20 \%$ of participants, this was designed to be pragmatic but may have amplified the results in relation to the true effectiveness of iron. However, only two participants received concurrent EPO, and this study was excluded during sensitivity analysis. In addition, observed improvements in LoS should be considered on a background of general reductions in LoS for elective THR or TKR over time. ${ }^{6364}$

\section{CONCLUSION}

Based on the best available evidence, preoperative anaemia management with iron in participants undergoing elective THR or TKR significantly reduces the number of participants requiring RBC transfusion, the number of units transfused and LoS. However, these results should be interpreted with a caution as highquality evidence is lacking.

Twitter Ashley B Scrimshire @abscrimshire and Alison Booth @AliBooth42

Acknowledgements We would like to thank Prasanna Sarathy and lyn-Hyang Lee for their assistance in the translation, data extraction and quality assessment of the two non-English papers.

Contributors $\mathrm{ABS}$ : designing the meta-analysis, collecting and analysing the data, preparing and writing the manuscript. AB: assisted in study design, collecting and analysing data, approving the manuscript. CF: assisted with statistical analysis, approving the manuscript. AK: assisted with conceptualising the study and approving the manuscript MR: assisted with conceptualising the study and approving the manuscript. CM: assisted with study design and approving the manuscript.

Funding The authors have not declared a specific grant for this research from any funding agency in the public, commercial or not-for-profit sectors.

Competing interests

Patient consent for publication Not required.

Provenance and peer review Not commissioned; externally peer reviewed.

Data availability statement All data relevant to the study are included in the article or uploaded as online supplemental information.

Supplemental material This content has been supplied by the author(s). It has not been vetted by BMJ Publishing Group Limited (BMJ) and may not have been peer-reviewed. Any opinions or recommendations discussed are solely those of the author(s) and are not endorsed by BMJ. BMJ disclaims all liability and responsibility arising from any reliance placed on the content. Where the content includes any translated material, BMJ does not warrant the accuracy and reliability of the translations (including but not limited to local regulations, clinical guidelines, terminology, drug names and drug dosages), and is not responsible for any error and/or omissions arising from translation and adaptation or otherwise.

Open access This is an open access article distributed in accordance with the Creative Commons Attribution Non Commercial (CC BY-NC 4.0) license, which permits others to distribute, remix, adapt, build upon this work non-commercially, and license their derivative works on different terms, provided the original work is properly cited, appropriate credit is given, any changes made indicated, and the use is non-commercial. See: http://creativecommons.org/licenses/by-nc/4.0/.

\section{ORCID iDs}

Ashley B Scrimshire http://orcid.org/0000-0002-7784-5891

Alison Booth http://orcid.org/0000-0001-7138-6295

Catriona McDaid http://orcid.org/0000-0002-3751-7260

\section{REFERENCES}

1 Brittain R, Young E, Mccormack V, et al. National joint Registry for England, Wales, Northern Ireland and the Isle of man, 16th annual report, 2019. Available: https://reports.njrcentre.org.uk/Portals/0/ PDFdownloads/NJR

2 Muñoz M, Laso-Morales MJ, Gómez-Ramírez S, et al. PreOperative haemoglobin levels and iron status in a large multicentre cohort of patients undergoing major elective surgery. Anaesthesia 2017;72:826-34.

3 Moltó L, Bisbe E, Arroyo R, et al. Utility of intravenous iron treatment for preoperative anemia with absolute or functional iron deficiency in orthopedic elective surgery patients. Eur J Anaesthesiol 2010;27:112.

4 Abdullah HR, Ranjakunalan N, Yeo W, et al. Association between preoperative anaemia and blood transfusion with long-term functional and quality of life outcomes amongst patients undergoing primary total knee arthroplasty in Singapore: a single-centre retrospective study. Qual Life Res 2019;28:85-98. 
5 Saleh E, McClelland DBL, Hay A, et al. Prevalence of anaemia before major joint arthroplasty and the potential impact of preoperative investigation and correction on perioperative blood transfusions. $\mathrm{Br} \mathrm{J}$ Anaesth 2007;99:801-8.

6 Lloyd TD, Neal-Smith G, Fennelly J, et al. Peri-Operative administration of tranexamic acid in lower limb arthroplasty: a multicentre, prospective cohort study. Anaesthesia 2020;75:1050-8.

7 Musallam KM, Tamim HM, Richards T, et al. Preoperative anaemia and postoperative outcomes in non-cardiac surgery: a retrospective cohort study. Lancet 2011;378:1396-407.

8 Goodnough LT, Maniatis A, Earnshaw P, et al. Detection, evaluation, and management of preoperative anaemia in the elective orthopaedic surgical patient: NatA guidelines. Br J Anaesth 2011;106:13-22.

9 Voorn VMA, van der Hout A, So-Osman C, et al. Erythropoietin to reduce allogeneic red blood cell transfusion in patients undergoing total hip or knee arthroplasty. Vox Sang 2016;111:219-25.

10 Nice guideline NG24 methods, evidence and recommendations. Nat/ Inst Heal Care Excell 2015.

11 Anaesthetists RC of. Scottish standard for the optimisation of preoperative anaemia, 2018. Available: www.rcoa.ac.uk [Accessed 28 Feb 2019].

12 Muñoz M, Acheson AG, Auerbach M, et al. International consensus statement on the peri-operative management of anaemia and iron deficiency. Anaesthesia 2017;72:233-47.

13 Mueller M, Van Remoortel H, Meybohm P, et al. Patient blood management: recommendations from the 2018 Frankfurt consensus conference. J Am Med Assoc 2019;321:983-97.

14 Royal College of Anaesthetists. Perioperative quality improvement programme, Annual report 2018-19 [Internet], 2018. Available: https://pqip.org.uk/FilesUploaded/PQIP Annual Report 2018-19.pdf

15 Althoff FC, Neb H, Herrmann E, et al. Multimodal patient blood management program based on a Three-pillar strategy. Ann Surg 2018:1.

16 Kaserer A, Rössler J, Braun J, et al. Impact of a patient blood management monitoring and feedback programme on allogeneic blood transfusions and related costs. Anaesthesia 2019;74:1534-41.

17 Leahy MF, Hofmann A, Towler S, et al. Improved outcomes and reduced costs associated with a health-system-wide patient blood management program: a retrospective observational study in four major adult tertiary-care hospitals. Transfusion 2017;57:1347-58

18 Sukeik M, Alshryda S, Haddad FS, et al. Systematic review and meta-analysis of the use of tranexamic acid in total hip replacement $J$ Bone Joint Surg Br 2011;93:39-46.

19 Carson JL, Stanworth SJ, Roubinian N, et al. Transfusion thresholds and other strategies for guiding allogeneic red blood cell transfusion. Cochrane Database Syst Rev 2016;10:CD002042.

20 Muñoz M, Gómez-Ramírez S, Kozek-Langeneker S, et al. 'Fit to fly': overcoming barriers to preoperative haemoglobin optimization in surgical patients. Br J Anaesth 2015;115:15-24.

21 Nhs blood and transplant. National comparative audit of blood transfusion 20162016.

22 WHO. Worldwide prevalence of anaemia: 1993 - 2005. 51. WHO Rep, 2005.

23 Wells G, Shea B, O'Connell D, et al. The Newcastle-Ottawa scale (NOS) for assessing the quality of nonrandomised studies in meta-analyses. Available: http://www.ohri.ca/programs/clinical_ epidemiology/oxford.asp

24 Higgins JPT, Altman DG, Gøtzsche PC, et al. The Cochrane collaboration's tool for assessing risk of bias in randomised trials. BMJ . 2011;343:d5928 https://www.bmj.com/content/343/bmj.d5928

25 Oteng-Ntim E, Mononen S, Sawicki O, et al. Interpregnancy weight change and adverse pregnancy outcomes: a systematic review and meta-analysis. BMJ Open 2018;8:e018778-14.

26 Higgins J. Green (editors) S, Green S (editors). Cochrane Handbook for Systematic Reviews of Interventions Version 5.1.0 [updated March 2011] The Cochrane Collaboration [Internet]. The Cochrane Collaboration, 2011. Available: www.handbook.cochrane.org

27 Munting KE, Klein AA. Optimisation of pre-operative anaemia in patients before elective major surgery - why, who, when and how? Anaesthesia 2019;74 Suppl 1:49-57 http://onlinelibrary.wiley.com/ journal/

28 Scardino M, Di Matteo B, Martorelli F, et al. Improved patient blood management and cost saving in hip replacement surgery through the implementation of pre-operative Sucrosomial ${ }^{\circledR}$ iron supplementation: a quality improvement assessment study. Int Orthop 2019;43:39-46.

29 Gonzalez-Porras JR, Colado E, Conde MP, et al. An individualized pre-operative blood saving protocol can increase pre-operative haemoglobin levels and reduce the need for transfusion in elective total hip or knee arthroplasty. Transfus Med 2009;19:35-42.

30 Litton E, Xiao J, Ho KM. Safety and efficacy of intravenous iron therapy in reducing requirement for allogeneic blood transfusion: systematic review and meta-analysis of randomised clinical trials. BMJ 2013;347:f4822-10.

31 Pujol-Nicolas A, Morrison R, Casson C, et al. Preoperative screening and intervention for mild anemia with low iron stores in elective hip and knee arthroplasty. Transfusion 2017;57:3049-57.

32 Harbord RM, Higgins JPT. Meta-Regression in Stata. Stata J 2008;8:493-519.

33 Pinilla-Gracia C, Mateo-Agudo J, Herrera A, et al. On the relevance of preoperative haemoglobin optimisation within a patient blood management programme for elective hip arthroplasty surgery. Blood Transfus 2020;18:182-90.

34 Bisbe E, García-Erce JA, Díez-Lobo Al, et al. A multicentre comparative study on the efficacy of intravenous ferric carboxymaltose and iron sucrose for correcting preoperative anaemia in patients undergoing major elective surgery. $\mathrm{Br} \mathrm{J}$ Anaesth 2011;107:477-8

35 Costanzo M. Effectiveness of oral Sucrosomial $\circledast$ iron (Sideral $®$ Forte) administration in patients undergoing hip replacement. Expert Rev Hematol 2017;10:15-16.

36 Khalafallah Aet al. A prospective randomized controlled trial to assess the effect of intravenous versus oral iron therapy in the treatment of preoperative anaemia. J Blood Disord Transfus 2012;03.

37 Bae KC, Cho CH, Lee KJ, et al. The effects of preoperatively administering parenteral iron sucrose in patients who are undergoing total knee arthroplasty 2010;22:124-9.

38 Heschl M, Gombotz H, Haslinger-Eisterer B, et al. The efficacy of preoperative preparation with intravenous iron and/or erythropoietin in anaemic patients undergoing orthopaedic surgery: an observational study. Eur J Anaesthesiol 2018;35:289-97.

39 Razurel A, Dupont X, Politis B, et al. Supplémentation pré-opératoire de Fer oral en Prévention des anémies aiguës post-opératoires en Chirurgie orthopédique. J Pharm Clin 2014;33:21-31.

40 Myers E, O'Grady P, Grady PO, et al. The influence of preclinical anaemia on outcome following total hip replacement. Arch Orthop Trauma Surg 2004;124:699-701.

41 Andrews CM, Lane DW, Bradley JG. Iron pre-load for major joint replacement. Transfus Med 1997;7:281-6.

42 Yang Y, Li H, Li B, et al. Efficacy and safety of iron supplementation for the elderly patients undergoing hip or knee surgery: a meta-analysis of randomized controlled trials. J Surg Res 2011:171:e201-7.

43 Spahn DR. Anemia and patient blood management in hip and knee surgery. Anesthesiology 2010;113:482-95.

44 Alexander DP, Frew N. Preoperative optimisation of anaemia for primary total hip arthroplasty: a systematic review. Hip Int 2017;27:515-22.

45 Shin HW, Park JJ, Kim HJ, et al. Efficacy of perioperative intravenous iron therapy for transfusion in orthopedic surgery: a systematic review and meta-analysis. PLoS One . 2019;14:e0215427.

$46 \mathrm{Ng} \mathrm{O}$, Keeler BD, Mishra A, et al. Iron therapy for pre-operative anaemia (review). Cochrane Database Syst Rev 2015.

47 Schack A, Berkfors AA, Ekeloef S, et al. The effect of perioperative iron therapy in acute major non-cardiac surgery on allogenic blood transfusion and postoperative haemoglobin levels: a systematic review and meta-analysis. World J Surg 2019;43:1677-91.

48 Lin DM, Lin ES, Tran M-H. Efficacy and safety of erythropoietin and intravenous iron in perioperative blood management: a systematic review. Transfus Med Rev 2013;27:221-34.

49 Froessler B, Tufanaru C, Cyna A, et al. Preoperative anemia management with intravenous iron: a systematic review. $J B I$ Database System Rev Implement Rep 2013;11:157-89.

50 Le Manach Y, Collins G, Bhandari M, et al. Outcomes after hip fracture surgery compared with elective total hip replacement. JAMA 2015;314:1159-66.

51 Carson JL, Stanworth SJ, Roubinian N, et al. Transfusion thresholds and other strategies for guiding allogeneic red blood cell transfusion. Cochrane Database Syst Rev . 2016;10:CD002042.

52 Ker K, Edwards P, Perel P, et al. Effect of tranexamic acid on surgical bleeding: systematic review and cumulative meta-analysis. BMJ 2012;344:1-13

53 Goddard AF, James MW, Mclntyre AS, et al. Guidelines for the management of iron deficiency anaemia. Gut 2011;60:1309-16.

54 Muñoz M, Peña-Rosas JP, Robinson S, et al. Patient blood management in obstetrics: management of anaemia and haematinic deficiencies in pregnancy and in the post-partum period: NatA consensus statement. Transfus Med 2018:28:22-39.

55 Gómez-Ramírez S, Brilli E, Tarantino G, et al. Sucrosomial $\AA$ iron: a new generation iron for improving oral supplementation. Pharmaceuticals 2018;11:97-23.

56 Rognoni C, Venturini S, Meregaglia M, et al. Efficacy and safety of ferric carboxymaltose and other formulations in iron-deficient 
patients: a systematic review and network meta-analysis of randomised controlled trials. Clin Drug Investig 2016;36:177-94.

57 Muñoz M, Gómez-Ramírez S, Cuenca J, et al. Very-ShortTerm perioperative intravenous iron administration and postoperative outcome in major orthopedic surgery: a pooled analysis of observational data from 2547 patients. Transfusion 2014;54:289-99.

58 Moher D, Liberati A, Tetzlaff J, et al. Preferred reporting items for systematic reviews and meta-analyses: the PRISMA statement. $J$ Clin Epidemiol 2009;62:1006-12.

59 Sharma M, Nazareth I, Petersen I. Observational studies of treatment effectiveness: worthwhile or worthless? Clin Epidemiol 2019;11:35-42.

60 Afshari A, Wetterslev J, Smith AF. Can systematic reviews with sparse data be trusted? Anaesthesia 2017;72:12-16.

61 Tolkien Z, Stecher L, Mander AP, et al. Ferrous sulfate supplementation causes significant gastrointestinal side-effects in adults: a systematic review and meta-analysis. PLoS One 2015;10:e0117383.
62 Alleyne M, Horne MK, Miller JL. Individualized treatment for irondeficiency anemia in adults. Am J Med 2008;121:943-8.

63 Burn E, Edwards CJ, Murray DW, et al. Trends and determinants of length of stay and hospital reimbursement following knee and hip replacement: evidence from linked primary care and NHS Hospital records from 1997 to 2014. BMJ Open 2018;8:e19146.

64 Lazic S, Boughton O, Kellett CF, et al. Day-Case surgery for total hip and knee replacement. EFORT Open Rev [Internet] 2018;3:130-5.

65 Ganzoni AM. [Intravenous iron-dextran: therapeutic and experimental possibilities]. Schweiz Med Wochenschr 1970;100:301-3.

66 Carneiro IA, Drakeley CJ, Owusu-Agyei S, et al. Haemoglobin and haematocrit: is the threefold conversion valid for assessing anaemia in malaria-endemic settings? Malar J [Internet] 2007;6:67.

67 Hozo SP, Djulbegovic B, Hozo I. Estimating the mean and variance from the median, range, and the size of a sample. BMC Med Res Methodol 2005;5:1-10.

68 Bland M, Bland M. Estimating mean and standard deviation from the sample size, three Quartiles, minimum, and maximum. Int J Stat Med Res 2015;4:57-64. 